\title{
Dietary intake and retinal microvasculature: a systematic review
}

\author{
Stuart Keel ${ }^{1}$, Connie Koklanis ${ }^{1}$, Meri Vukicevic ${ }^{1}$, \\ Catherine Itsiopoulos², Laima Brazionis ${ }^{3}$ \\ 'Department of Clinical Vision Sciences, Latrobe University, Melbourne, Australia; \\ ${ }^{2}$ Department of Dietetics, Latrobe University, Melbourne, Australia; ${ }^{3}$ Department of \\ Medicine, University of Melbourne, St Vincent's Hospital, Melbourne, Australia
}

\begin{abstract}
Aims: To summarise the available findings from published research that has focussed on the effect of diet on retinal microvascular characteristics.

Design: Systematic review.

Methods: A systematic Medline, EMBASE and PubMed search of relevant articles was conducted with coverage from the January 1, 1970 up to the January 10, 2013. Search terms were pilot tested for accuracy and modified. Articles were systematically excluded if the title and abstract were not relevant and full text manuscripts were obtained for all studies that were potentially relevant.

Results: After combining all searches, 5370 abstracts were identified and screened. Of these 20 were considered potentially relevant and full articles were retrieved for further evaluation. Eleven of these studies did not meet the inclusion/exclusion criteria, leaving 9 studies to be included in the review.

Conclusions: To date, it has been suggested that a low glycemic Index (GI) diet, high dietary fibre intake and regular fish consumption attenuate retinal arteriolar narrowing and retinal venular widening which has been associated with adverse cardiovascular outcomes. Conversely, it has been suggested that a high Gl diet may predispose an individual to adverse retinal microvascular changes.
\end{abstract}

Keywords: Microvasculature, retinal blood flow, retinal vascular calibre, diet, nutrition.

\section{Background}

Retinal blood vessels are readily viewable via non-invasive retinal photography. ${ }^{1}$ Previous methods of measuring retinal vascular characteristics involved subjective clinical examination of arterio-venous ratio (AVR) via fundoscopy, which proved variable and of limited value as a predictor of increased risk of cardiovascular related diseases. More recently, reproducible computer-based imaging programs have been employed to quantitatively measure retinal vasculature. ${ }^{2}$ These assessments provide a means to study early structural changes that provide important information regarding the state of retinal microcirculation. ${ }^{3}$

The vascular architecture of the retina is believed to follow an optimal pattern which allows for best possible blood distribution while utilising the least amount of energy. ${ }^{4}$ Any deviations from this normal structure, most notably in the form of retinal arteriolar narrowing and retinal venular dilation, can be an indication of

Correspondence: Mr Stuart Keel, 60 Malmsbury Street, Kew, Victoria, 3101, Austrailia.

E-mail: s.keel@latrobe.edu.au 
pathogenic processes. ${ }^{4}$ Research suggests that retinal microvascular dysfunction may be a predictive factor in the development of various cardiovascular, cerebrovascular and metabolic-related diseases. ${ }^{5}$ Strong associations have been found between wider retinal venular calibre and narrower retinal arteriolar calibre and the incidence of coronary heart disease (CHD) ${ }^{6}$ and vascular abnormalities in cerebral microcirculation. ${ }^{5}$ Furthermore, a definitive link between narrower retinal arteriolar calibre and hypertension development ${ }^{7}$ and wider retinal venular calibre and the increased risk of incident stroke ${ }^{8}$ has been reported in the literature.

Previous research has established strong links between diet and the development of macrovascular ${ }^{9-11}$ and microvascular complications. ${ }^{12,13}$ To date, several studies have suggested that diet may be a determinant of retinal vascular structure. Dietary fibre and fish consumption as well as the consumption of high glycemic index (Gl) foods have been associated with retinal vascular alterations. Despite this, large gaps in current knowledge exist, including the association between diet and retinal vascular calibre in healthy children and adolescents. This information would reveal the physiological influence of diet on microcirculation while minimising confounding systemic factors. The main aim of this review is to summarise the available information from published research that has focussed on the effect of diet on retinal microvascular characteristics.

\section{Methods}

\section{Information sources and search strategy}

A systematic Medline, EMBASE and PubMed search of relevant articles was conducted with coverage from the January 1, 1970 up to the January 10, 2013. Search terms were pilot tested for accuracy and modified until a final search strategy could be used to achieve the desired outcome using all 3 databases. All searches included a combination of the key terms: retinal vascular calibre, retinal vascular caliber, retinal dilatation, retinal blood flow, retinal blood vessel*, retinal vessel*, retinal vessel diameter, retinal microvascular caliber, diet*, food, nutrition and nutrients. The search was not restricted by language but was limited to studies conducted in humans. The reference lists of retrieved articles were utilised to identify additional resources.

\section{Study selection}

Two reviewers (SK \& KK) independently searched the 3 databases and screened the resultant titles and abstracts. Articles were systematically excluded if the title and abstract were not relevant and full text manuscripts were obtained for all studies that were potentially relevant.

\section{Eligibility and exclusion criteria}

Randomised controlled trials, prospective, retrospective, cohort, case control, and cross sectional studies were eligible for inclusion in the review. Studies that involved any dietary factor and incorporated retinal vessel characteristics as a primary outcome measure were included. There was no restriction placed on the 
method of vascular microvascular analysis. Nor was there any restriction on participant ethnicity. Those studies that examined associations between lifestyle factors (E.g. smoking, supplement consumption and physical activity) and retinal microvasculature were excluded. Review articles were excluded.

\section{Results}

After combining all searches, 5370 abstracts were identified and screened. Of these 20 were considered potentially relevant and full articles were retrieved for further evaluation. Eleven of these studies did not meet the inclusion/exclusion criteria, leaving 9 studies to be included in the review (Table 1). Of the excluded studies, 3 were review articles, 2 were duplicates and 6 did not directly examine the association between dietary factors and retinal vasculature (Fig 1). There was complete agreement between the reviewers for eligibility. A meta-analysis was not performed due to the small number of articles.

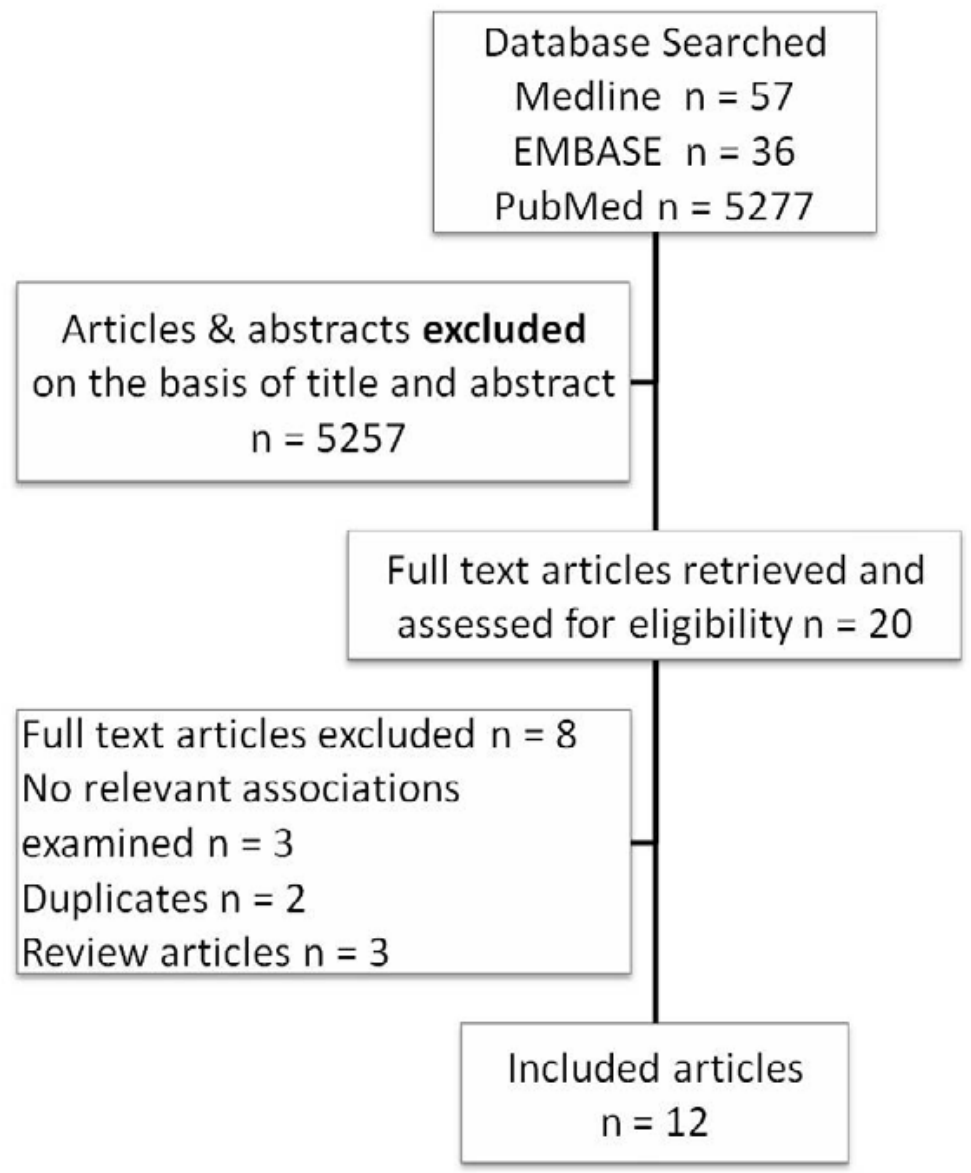

Fig 1. Summary of study selection process 


\section{Glycemic index}

Dietary glycemic index $(\mathrm{Gl})$ provides a measure of carbohydrate quality, ranking carbohydrates according to their effect on postprandial blood glucose excursions. ${ }^{14}$ Previous studies have suggested that diets high in cereal fibre are associated with a lower risk of cardiovascular disease and lower blood pressure. ${ }^{14}$ Conversely, it has been proposed that in the absence of a high fibre diet, diets with a high glycemic load have been associated with small vessel dysfunction and therefore may contribute to the development of diabetes, cardiovascular disease and stroke. ${ }^{15}$ Gopinath ${ }^{14}$ examined the effects of high-Gl and high-glycemic load diets, carbohydrates and main carbohydrate containing food groups on retinal vascular calibre changes in 2353 pre-adolescent individuals and found that those children who consumed soft drink once or more per day had a narrower retinal arteriolar calibre than those who never or rarely consumed soft drinks $(p=0.03)$. A higher-Gl diet was associated with narrower retinal arteriolar calibre in girls only. Overall, a greater consumption of carbohydrates and soft drinks was associated with narrower retinal arterioles $(p=0.01)$ and wider retinal venules $(p=0.002)$. As previous research $h^{6,8,16}$ has found associations between microvascular signs of narrower retinal arterioles and wider venules to the future risk of cardiovascular disease this finding may support the promotion of healthy dietary patterns, including lower consumption of soft drinks and high-Gl foods to children.

In alignment with Gopinath's ${ }^{14}$ findings, associations between a high-Gl diet and wider retinal venular calibre have also been found in adults. ${ }^{17}$ Kaushik ${ }^{17}$ assessed the relationship between dietary-Gl and low cereal fibre and retinal vascular calibre characteristics in a large cohort of individuals $(n=2897)$ over the age of 49 years and noted that a higher dietary-GI and lower cereal fibre intake were associated with wider retinal venular calibre $(p=<0.01)$. They further suggested that higher dietary$\mathrm{Gl}$ and lower cereal fibre intakes were associated with double the risk of stroke related death, suggesting that a high-Gl diet may produce adverse changes in the bodies microvasculature. ${ }^{17}$ Although the mechanisms underlying the changes in retinal venular calibre are still largely unknown it has been postulated that a high Gl diet may result in the formation of advanced glycation end products in venular walls resulting in endothelial dysfunction and vascular damage..$^{15,18}$

\section{Dietary fibre}

Diets high in dietary fibre have been associated with a reduced risk of cardiovascular morbidity. ${ }^{19}$ Previous researchers have suggested that fibre may guard against hypertension, dislipidemea and incident diabetes by attenuating arteriolar narrowing and venular widening, which are emerging risk factors associated with these conditions.,20,21 To date, only one study has examined the association between dietary fibre intake and retinal vascular calibre in adults. ${ }^{22}$ The Atherosclerosis Risk in Communities Study (ARIC) recruited a large sample $(n=15,792)$ of white and African Americans and found that a higher intake of fibre was associated with wider retinal arteriolar calibre $(p=0.002)$ and narrower retinal venular calibre $(p=0.011)$. These findings are associated with a lower risk of cardiovascular disease 
and support other findings in highlighting the benefit of fibre intake in protecting against cardiovascular disease. By contrast, a similar population based cohort study conducted on children is not in agreement with these findings. ${ }^{23} \mathrm{Lim}^{23}$ assessed the relationship between dietary fibre along with a number of other dietary factors (protein, fat, cholesterol, carbohydrate and sugar intakes per day) and retinal vascular calibre in 823 healthy Singapore Chinese children (mean age; 12.8 \pm 0.8 ) and found that no significant association existed between any of the dietary constituents and retinal vascular calibre. These findings suggest that the effect of diet on microvasculature may only become evident later in life which could provide evidence for a potential cumulative effect of diet on the retinal microvasculature. ${ }^{23}$ Despite this, additional research is required to clarify these findings as unexplained or unmeasured confounders may exist.

\section{Fish consumption}

Omega-3 polyunsaturated fatty acids appear to lower the risk of CHD and stroke..$^{24}$ To date only one study has examined the effects of fish consumption on retinal microvasculature. ${ }^{24}$ Kaushik ${ }^{24}$ utilised a large sample $(n=2683)$ of Australian adults (>49yrs) and found higher frequency of fish consumption was significantly associated with wider retinal arteriolar $(p=0.002)$ and narrower retinal venular calibre $(p=0.02)$. These findings suggest that a higher consumption of fish may help protect against vascular changes associated with coronary heart disease and stroke. ${ }^{24}$ This association, however, was mainly seen in persons with hypertension which may confound the outcome as retinal microvascular changes have been strongly associated with hypertension in adults. As this is the only study to date to evaluate the association between fish consumption and retinal vascular calibre before any conclusions can be drawn concerning this relationship further research needs to be conducted.

\section{Antioxidants}

Several studies have highlighted the potential benefit of selected antioxidants on various eye diseases such as diabetic retinopathy, uveitis and age related macula degeneration. ${ }^{25-28}$ However, the relationship between antioxidants and retinal vasculature remains poorly understood. Pemp's $\mathrm{s}^{29}$ study on 21 adults aged 18-35 years found that the administration of antioxidants attenuated arteriolar vasoconstriction during systemic hypoxia $(p=0.04)$. This supports the suggestion that antioxidants may reduce oxidative stress by reducing reactive oxygen species which has been shown to contribute to cellular damage through endothelial dysfunction..$^{29}$ Although these results suggests that dietary antioxidant consumption may be associated with positive microvascular outcomes, no inferences can be made until the long term relationship between antioxidant intake and retinal vascular calibre is explored.

\section{Caffeine}

Caffeine is the most frequently consumed stimulant worldwide, acting by increasing blood pressure while increasing heart rate. Several studies have demonstrated the 
effects of caffeine on cerebral, coronary and ocular blood flow. ${ }^{30-32} \mathrm{~A}$ small prospective study $(n=17)$ by Terai ${ }^{33}$ is the only study to date that has investigated the effect of caffeine on retinal vessel diameter. A significant vasoconstrictory response of retinal arterioles ( $p=0.004$ ) and venules $(0.005)$ occurred one hour following caffeine intake. ${ }^{34}$ This finding is consistent with earlier studies that assessed the effect of caffeine on retinal circulation and found that caffeine significantly reduced retinal blood flow in the optic nerve head and choroid retina. ${ }^{30,35}$ It has been hypothesised that these changes may be elicited by an auto-regulatory response of retinal blood vessels to the increased blood pressure changes associated with caffeine intake. Despite this, these results must be viewed with caution due to the small sample size and the fact a control group was not employed to control for non-drug related effects on the measured variables. Furthermore, Terai's ${ }^{33}$ findings are contradictory to previous research that has suggested that the long term influence of high caffeine consumption is not associated with cardiovascular disease risk ${ }^{36}$ and in fact may lower the risk of type 2 diabetes in younger to middle aged women. ${ }^{37}$ This highlights the need for further research before any judgements can be made on the role caffeine plays on human microvasculature.

\section{Salt Intake}

The role of sodium intake in end organ damage remains largely unknown, however, it is increasingly becoming a focus of researchers due to its well described association with cardiovascular disease. Most notably, strong associations have been reported between high sodium intake and systolic hypertension. ${ }^{38}$ Raff ${ }^{39}$ analysed the association between salt intake and retinal arteriolar structure in 40 adults aged 44-75 years with treatment resistant hypertension. They found that retinal arteriole wall thickness was directly associated with urinary sodium excretion $(p=0.008)$. This suggests that salt intake may influence the structure of retinal arterioles, independent of blood pressure..$^{39}$ However, as this study examined only structural changes in arterioles, the results cannot be directly related to retinal vascular diameter measurements. Furthermore, these results may be confounded by the presence of treatment resistant hypertension in participants as well as the use of multiple antihypertensive drug therapies which have been shown to have different influences on vascular structure. ${ }^{40,41}$ Further research is required to aid in understanding the relationship between sodium intake and retinal microvasculature. These studies should utilise standardised methods for retinal vascular calibre assessment and focus on non-hypertensive participants as high current and previous blood pressure has been consistently associated with retinal arteriolar narrowing in children and adult cohorts. ${ }^{42-45}$

\section{Plant sterol and-stanol consumption}

Sterols such as sitosterol and campesterol are derived from various plant products such as plant oils, nuts and seeds. Sterol and -stanol are often used as additives in foods such as margarine to reduce serum LDL cholesterol concentrations. ${ }^{46}$ Although these products have been suggested to lower cardiovascular risk, some researchers have indicated that high sterol concentrations may be atherogenic 
(the deposition of atheromas, lipids, and calcium in the arterial lumen). ${ }^{46}$ Kelly's $s^{46}$ randomised control trial on 30 participants aged 18 to 65 years is the only study to date to assess the effects of long term plant sterol and -stanol consumption on retinal vessel diameter changes. They found that increased serum campesterol concentrations were associated with a wider retinal venular diameter $(p=0.033)$. These results suggest that plant sterols may be a biomarker for pathological vascular function. However, before any judgements can be made on plant sterol rich foods further research into the relationship between plant sterol consumption and our microvascular system is required.

\section{Discussion}

Previous research has found associations between reduced risk of vascular disease and the regular consumption of fish, dietary fibre and low Gl foods. Therefore, the finding that some correlation exists between diet and retinal vessel diameter could be expected and may not add to clinical practice..$^{47,48}$ However, emerging evidence has highlighted that the relationship between diet and vascular disease may in fact be partly mediated by associated changes in the microcirculation. ${ }^{17,22,24}$ As such, the use of retinal imaging to visualise human microcirculation may potentially provide additional prognostic information beyond current traditional risk factors.

To date it has been suggested that a low Gl diet, high dietary fibre intake, and greater frequency of fish consumption may protect against vascular disease by attenuating retinal arteriolar narrowing and retinal venular widening. ${ }^{17,22,24}$ Conversely, it has been suggested that a high Gl diet may predispose an individual to adverse microvascular changes. ${ }^{14}$ Although some link between changes in retinal microvasculature and caffeine and antioxidants intake has been suggested, further research is required before any judgements can be made as only short term changes were examined. Furthermore, it is difficult to draw inferences into the role sodium and sterol and -stanol play on human microvasculature until dietary intakes of these agents are the primary exposure.

Emerging evidence suggests that retinal vascular calibre assessment has the potential to become a tool to better understand the pathophysiology of the body's microvasculature and aid in the prediction of several vascular diseases. ARIC found that wider retinal venular calibre and narrower retinal arteriolar calibre were associated with a 10 year increased risk of incident $\mathrm{CHD}$ in women. ${ }^{6}$ Retinal arteriolar narrowing has also been found to precede the development of clinical hypertension by years in patients who displayed blood pressure in the normal range at baseline. ${ }^{5}$ It has been postulated that decreases in internal arteriolar lumen calibre occur early in the development of hypertension and these changes are responsible for altering the body's hemodynamics and ultimately resetting blood pressure to a higher level. ${ }^{5,749}$ Furthermore, changes in retinal arterioles have been linked to changes in small cerebral arteries that cause white matter lesions, while the presence and severity of coronary artery occlusion has also been strongly associated with vascular calibre changes. ${ }^{5,50} \mathrm{~A}$ wider retinal venular calibre on the other hand, has been to increased risk of incident stroke, independent of traditional risk factors. ${ }^{8}$ 
The mechanisms behind the retinal microvascular changes in calibre are incompletely understood. Possible mechanisms for the development of smaller retinal arteriolar calibre is that it is associated with hypertensive and arteriosclerotic microvascular changes, endothelial dysfunction, and inflammatory changes which are thought to be involved in the pathogenesis of various cardiovascular diseases.51,52 A widening of retinal venular calibre on the other hand, may reflect an increase in blood flow to maintain the tissue oxygen levels which also may be attributed to the reduced supply of nutrients and an increased concentration of waste products, e.g. lactic acidosis associated with retinal hypoxia. ${ }^{53,54}$ An alternate hypothesis behind venular dilation suggests that inflammation associated with increased nitrous oxide levels may be partly responsible for this variation in retinal venules..$^{55}$ From this it appears that variations in retinal arteriolar and venular calibre may reflect different pathophysiological processes.

Whilst many of these studies ${ }^{14,17,22-24}$ included large sample sizes, caution must be observed in interpreting the findings of Raff, ${ }^{39} \mathrm{Pemp}_{1}{ }^{29} \mathrm{Terai}^{34}$ and Kelly ${ }^{46}$ due to the inclusion of a relatively small sample sizes. Furthermore, several studies included in this review ${ }^{29,30,34,35,39}$ did not utilise standard protocols for retinal vascular diameter assessment and therefore the results must be viewed cautiously. Additionally, some of the studies ${ }^{14,24}$ reported only small variations in retinal vascular calibre. Despite this, it has been shown that even a small reduction in retinal arteriolar calibre is associated with clinically significant changes in blood pressure. For example, a 1.1 micron reduction in arteriolar calibre was associated with a $10 \mathrm{mmHg}$ higher systolic blood pressure. ${ }^{56}$ As computerised methods are not available clinically, subjective AVR measurements may still have some utility clinically. More guidance surrounding AVR assessment is required in future research.

The majority of the studies included in this review most assessed associations between dietary factors and retinal microvasculature in adults. However, to develop an understanding of the effect of dietary factors on retinal vessels the study of calibre in children may provide additional insights as they are generally exposed to fewer potentially confounding systemic and environmental factors than adults. Lim's ${ }^{23}$ study suggested that the effect of diet on microvasculature may only become evident later in life and therefore studying the effect of dietary factors on retinal vasculature in children is not warranted. ${ }^{23}$ However, the food frequency questionnaire utilised in that study was not validated in children and exposures that have been shown to influence retinal vasculature, such as birth parameters, were not assessed and as such their findings may have been confounded. Furthermore, more recent studies that have examined the effect of carbohydrates on retinal vascular calibre in children and young adults have found significant associations. ${ }^{14,34}$ These contradictory findings highlight that the physiological influence of diet on retinal vascular calibre remains relatively unclear.

In summary, an individual with a healthy diet, including low $\mathrm{Gl}$ foods, high dietary fibre intake and regular fish consumption, is more likely to have a characteristic retinal microvascular pattern of wider retinal arteriolar and narrower retinal venular diameters. Conversely, the opposite (narrower retinal arterioles and wider venules) 
is more likely in those with a poor diet, consisting of high intakes high-Gl foods. Narrower retinal arterioles and wider venules have been suggested to reflect microvascular dysfunction associated with the development of various cardiovascular, cerebrovascular and metabolic diseases. Despite this, it is important to note that most of the inferences in this review are based on the findings from one study and as such a major gap in the literature has been highlighted. Perhaps most importantly, the association between diet and retinal vascular calibre in healthy child and adult cohorts in whom the association is less likely to be confounded by disease states should be investigated.

\section{References}

1. Liew G, Wang J, Duncan B, Klein R, Sharrett A, Brancati F, Yeh H, Mitchell P, Wong T. Low birthweight is associated with narrower arterioles in adults. Hypertension AHA. 2008;51:933-8.

2. Wong T, Knudtson M, Klein R, Klein B, Meuer S, Hubbard L. Computer-assisted measurement of retinal vessel diameters in the Beaver Dam eye study: methodology, correlation between eyes, and effect of refractive errors. Ophthalmology. 2004;111(6):1183-90.

3. Cheung N, Islam A, Saw S, Shankar A, De Haseth K, Mitchell P, Wong T. Distribution and associations of retinal vascular caliber with ethnicity, gender, and birth parameters in young children. Investigative Ophthalmology \& Visual Science. 2007;48(3):1018-24.

4. Serre K, Sasongko M. Modifiable lifestyle and environmental risk factors affecting microcirculation. Microcirculation. 2011;19:29-36.

5. Liew G, Wang J, Mitchell P, Wong T. Retinal vascular imaging: a new tool in microvascular disease research. Circ Cardiovasc Imaging. 2008;1:156-61.

6. McGeechen K, Liew G, Macaskill P, Irwig L, Klein R, Sharrett A, Klein B, Wang J, Chambless L, Wong T. Risk prediction of coronary heart disease based on retinal vascular caliber. Am J Cardiol. 2008;102(1):58-63.

7. Wong T, Islam A, Klein R. Retinal vascular caliber, cardiovascular risk factors, and inflammation: the multi-ethnic study of atherosclerosis (MESA). Investigative Ophthalmology \& Visual Science. 2006;47(6):2341-50.

8. McGeechen K, Liew G, Macaskill P, Irwig L, Klein R, Klein B, Wang J, Mitchell P, Vingerling J, De Jong F, Witteman M, Breteler M, Shaw J, Zimmet $P$, Wong T. Prediction of incident stroke events on retinal vascular caliber: a systematic review and individual-participant meta-analysis. Am J Epidemiol. 2009;170:1323-32.

9. Kant A, Schatzkin A, Ziegler R. Diet diversity and subsequent cause-specific mortality. Am J Coll Nutr. 1995;14:233-8.

10. Kushi L, Lew R, Stare F, Ellison C, Lozy M, Bourke G, Daly L, Graham I, N K, Mulcahy R, Kevaney J. Diet and 20-year mortality from coronary heart disease: the Ireland-Boston diet-heart study. N Engl J Med. 1985;312:811-8.

11. Niklas $T$, Webber $L$, Thomson $B$, Berenson $G$. A multivariate model for assessing eating patterns and their relationship to cardiovascular risk factors: the bogalusa heart study. Am J Clin Nutr. 1989;49:1320-7.

12. Macready A, George T, Chong M, Alimbetov D, Jin Y, Vidal A, Spencer J, Kennedy O, Tuohy K, Minihane A, Gordon M, Lovegrove J. Flavonoid-rish fruit and vegetables improve microvascular reactivity and inflammatory status in men at risk of cardiovascular disease - FLAVURS: a randomized control trial. Am J Clin Nutr. 2014:1-11.

13. McCall D, McGartland C, McKinley M, Patterson C, Sharpe P, McCance D, Young I, Woodside J. Dietary intake of fruits and vegetables improves microvascular function in hypertensive subjects in a dose-dependent manner. Circulation. 2009;119:2153-60.

14. Gopinath B, Flood V, Wang J, Smith W, Rochtchina E, Louie J, Wong T, Brand-Miller J, Mitchell P. Carbohydrate nutrition is associate with changes in retinal vacular structure and branching pattern in children. Am J Clin Nutr. 2012;95:1215-22. 
15. Ross C. Carbohydrate intake, glycemic index, glycemic load, and dietary fiber in relation to risk of stroke in women. Am J Epidemiol. 2005;161:995.

16. Wong T, Islam A, Klein B, Cotch M, Castro C, Sharrett A, Shahar E. Retinal vascular caliber, cardiovascular risk factors, and inflammation: the multi-ethnic study of atherosclerosis (MESA). Investigative Ophthalmology \& Visual Science. 2006;47(6):2341-50.

17. Kaushik S, Wang J, Wong T, Flood V, Barclay A, Brand-Miller J, Mitchell P. Glycemic index, retinal vascular caliber, and stroke mortality. Journal of the American Heart Association. 2009;40:206-12.

18. Qi L, Meigs J, Liu S, Manson J, Mantzoros C. Dietary fiber and glycemic load, obesity, and plasma adiponectin levels in woman with type 2 diabetes. Diabetes Care. 2006;29:1501-5.

19. Bazzano L, He J, Ogden L, Loria C, Whelan P. Dietary fiber intake and reduced risk of coronary heart disease in US men and women: the national health andnutrition examination survey 1 Epidemiologic follow-up study. Arch Intern Med. 2003;163:1897-904.

20. Ascherio A, Hennekens $C$, Willett W. Prospective study of nutritional factors, blood pressure and hypertension among US women. Hypertension AHA. 1996;27:1065-72.

21. Stevens J, Ahn K, Juhnaeri D, Steffan L, Couper D. Dietary fibre intake and glycemic index and incidence of diabetes in African-Ameriacan and white adults. Diabetes Care. 2002;25:1715-21.

22. Kan H, Stevens J, Heiss G, Klein R, Rose K, London S. Dietary fiber intake and reinal vascular caliber in the atherosclerosis risk in communities study. Am J Clin Nutr. 2007;86:1626-32.

23. Lim L, Cheung N, Saw S, Yap M, Wong T. Does diet influence theretinal microvasculature in children? Journal of the American Heart Association. 2009;40:473-4.

24. Kaushik S, Wang J, Flood V, Liew G, Smith W, Mitchell P. Frequency of fish consumption, retinal vascular signs and vascular mortality. Microcirculation. 2008;15:27-36.

25. Bosch-Morell F, Roma J, Marin N. Role oxygen and nitrogen species in experimental uveitis: anti-inflammatory activity of the synthetic antioxidant ebselen. Free Radic Biol Med. 2002;33(5):669-75.

26. Brazionis L, Rowley K, Istiopoulos C, O'Dea K. Plasma carotenoids and diabetic retinopathy. British Journal of Nutrition. 2009;101:270-7.

27. Group A-REDSR. A randomized, placebo-controlled, clinical trial of high-dose supplementation with vitamins $C$ and $E$, beta caroene, and zinc for age-related macular degeneration and vision loss. Ophthalmol. 2001;119(10):1417-36.

28. Juhl B, Klein F, Christiansen J. Vitamin C treatment reduces transcapillary escape rate of albumin in type 1 diabetes. J Intern Med. 2004;15(7):428-35.

29. Pemp B, Polska E, Karl K, Lasta M, Minichmayr A, Garhofer G, Woltzt M, Schmetterer L. Effects of antioxidants on ocular blood flow and endothelial function in an endotoxin-induced model of oidative stress in humans. Investigative Ophthalmology \& Visual Science. 2010;51:2-6.

30. Lofti K, Grunwald J. The eeffect of caffeine on the human macular circulation. Investigative Ophthalmology \& Visual Science. 1991;32(12):3028-32.

31. Bottcher $m$, Czernin J, Sun K. Effect of caffeine on mycardial blood flow at rest and during pharmacological vasodilation. J Nucl Med. 1995;36:2012-21.

32. Mathew R, Wilson W. Caffeine-indiced changes in cerebral circulation. Sroke. 1985;16(814-817).

33. Terai N, Eberhard S, Lutz P, Lutz R. The effect of caffeine on retinal vessel diameter in young healthy subjects. Acta Ophthalmol. 2012;90:524-28.

34. Terai N, Spoerl E, Pillunat L, Stodmeister R. The effect of caffeine on retinal vessel diameter in young healthy subjects. Acta Ophthalmol. 2012;90:524-8.

35. Okuno T, Sugiyama T, Tominaga $M$, Kojima S, Ikeda T. Effects of caffeine on microcirculation of the human ocular fundus. Jpn J Ophthalmol. 2002;46:170-6.

36. Ding M, Bhupathiraju S, Satija A, Dam R, Hu F. Long-term coffee consumption and risk of cardiovascukar disease: a systematic review and a dose-response meta-analysis of prospective studies. Circulation AHA. 2013:1-16.

37. Dam R, Willett W, Manson J, Hu F. Coffee, caffeine and risk of type 2 diabetes. Diabetes Care. 2006;29(2):398-403.

38. Kupari M, Koskinen $P$, Virolainen J. Correlates of left ventricular mass in a population sample aged 36-37 years. Focus on lifestyle and salt intake. Circulation AHA. 1994;89(1041-1050). 
39. Raff U, Harazny J, Titze S, Schmidt M, Michelson G, Schmieder R. Salt intake determines retinal arteriolar structure in treatment resistant hypertension independent of blood pressure. Atherosclerosis. 2012;222:235-40.

40. Agabiti-Rosey E, Heagerty A, Rizzoni D. Effects of antihypertensive treatment on small artery remodelling. J Hypertens. 2009;27:1107-14.

41. Klein R, Myers K, Klein B, Zinman B, Gardiner R, Suissa S, Sinaiko A, Donnelly S, Goodyer P, Strand T, Mauer M. Relationship of blood pressure to retinal vessel diameter in type 1 diabetes mellitus. Arch Ophthalmol. 2010;128:198-205.

42. Hubbard L, Brothers R, King G, Clegg L, Klein R, Cooper L, Sharrett A, Davis M, Cai J. Methods for evaluation of retinal microvascular abnormalities associated with hypertension/sclerosis in the atherosclerosis risk in communities study. Ophthalmology. 1999;106(12):2269-80.

43. Mitchell P, Cheung N, De Haseth K, Taylor B, Rochtchina E, Islam A, Wang J, Mei Saw S, Wong T. Blood pressure and retinal arteriolar narrowing in children. Hypertension AHA. 2007;49:1156-62.

44. Sharrett A, Hubbard L, Cooper L, Sorlie P, Brothers R, Nieto F, Pinsky J, Klein R. Retinal arteriolar diameters and elevated blood pressure: the cardiovascular health study. Am J Epidemiol. 1999;150:263-70.

45. Wong T, Hubbard L, Klein R, Marino E, Kronmal R, Sharrett A, Siscovick D, Burke G, Tielsch J. Retinal microvascular abnormalities and blood pressure in older people: the cardiovascular health study. Br J Ophthalmology. 2002;86:1007-13.

46. Kelly E, Plat J, Mensink R, Berendschot T. Effects of long term plant sterol and -stanol consumption on the retinal vasculature: a randomised control trial in statin uses. Atherosclerosis. 2011;214:225-30.

47. King D. Dietary fiber, inflammation, and cardiovascular disease. Mol Nutr Food Res. 2005;49:594-600.

48. Kris-Etherton P, Harris W, Appel L. Fish consumption, fish oil, omega-3 fatty acids, and cardiovascular disease. Circulation. 2002;106:2747-57.

49. Klein R, Klein B, Knudtson M, Wong T, Tsai C. Are inflammatory factors related to retinal vessel caliber? the Beaver Dam eye study. Arch Ophthalmol. 2006;124:87-94.

50. Patton N, Aslam T, MacGillivray T, Pattie A, Deary I, Dhillon B. Retinal vascular image analysis as a potential screeing tool for cerebrovascular disease: a rationale based on homology between cerebral and retinal microvasculatures. J Anat. 2005;206:319-48.

51. Klein R, Klein B, Moss S, Wong T. Retinal vascular caliber and microvascular and macrovascular disease in type 2 diabetes: XXI: the wisconsin epidemiologic study of diabetic retinopathy. Ophthalmology. 2007;114(10):1884-92.

52. Wong T, Klein R, Sharrett A, Schmidt M, Pankow J, Couper D, Klein B, Hubbard L, Duncan B. Retinal arteriolar narrowing and risk of diabetes mellitus in middle-aged persons. JAMA. 2002;287(19):2528-32.

53. Klein R, Klein B, Moss S, Wong T, Sharrett A. Retinal vascular caliber in persons with type 2 diabetes. Ophthalmology. 2006;13(9):1488-96.

54. Sasongko M, Wang J, Donaghue K, Cheung N, Benitez-Aguirre P, Jenkins A, Hsu W, Lee M, Wong T. Alterations in retinal microvascular geometry in young type 1 diabetes. Diabetes Care. 2010;33(6):1331-6.

55. Islam A, Nguyen T, Wang J, Tai E, Shankar A, Saw S, Aung T, Lim S, Mitchell P, Wong T. Quantitative retinal vascular calibre changes in diabetes and retinopathy: the Singapore Malay eye study. Eye. 2009;23:1719-24.

56. Ikram M, De Jong F, Vingerling J, Witteman M, Hofman A, Breteler M, De Jong P. Are retinal arteriolar or venular diameters associated with markers for cardiovascular disorders? the Rotterdam study. Investigative Ophthalmology \& Visual Science. 2004;45:2129-34. 
Table 1. Studies examining the association between dietary factors and retinal microvasculature, by year of publication.

\begin{tabular}{|c|c|c|c|c|c|c|c|}
\hline $\begin{array}{l}\text { Reference; country/ } \\
\text { setting of study }\end{array}$ & $\begin{array}{l}\text { Nutrient/s } \\
\text { examined }\end{array}$ & $\begin{array}{l}\text { Sample size; } \\
\text { age }\end{array}$ & Ethnicity & Study type & $\begin{array}{l}\text { Method of } \\
\text { retinal vessel } \\
\text { measurement }\end{array}$ & Adjustments & Outcome; $p$ value \\
\hline $\begin{array}{l}\text { Terai et al (2012) } \\
\text { Germany }\end{array}$ & Caffeine & $\begin{array}{l}\mathrm{n}=17 \\
22-35 \mathrm{yrs}\end{array}$ & German & Prospective & $\begin{array}{l}\text { Retinal Vessel } \\
\text { Analyser }\end{array}$ & None stated & $\begin{array}{l}\text { Significant vasoconstrictory } \\
\text { response of retinal arteri- } \\
\text { olar }(p=0.004) \text { and venular } \\
\text { diameters }(p=0.005) \text { occurred } \\
\text { following caffeine intake }\end{array}$ \\
\hline $\begin{array}{l}\text { Raff et al (2012) } \\
\text { Germany }\end{array}$ & Sodium & $\begin{array}{l}\mathrm{n}=40 \\
44-75 \mathrm{yrs}\end{array}$ & German & Observational & $\begin{array}{l}\text { Scanning } \\
\text { laser Doppler } \\
\text { flowmetry }\end{array}$ & Age \& BMI & $\begin{array}{l}\text { Vessel diameter of retinal } \\
\text { arterioles was associated with } \\
\text { urinary sodium excretion } \\
(\mathrm{p}=0.008)\end{array}$ \\
\hline $\begin{array}{l}\text { Gopinath et al (2012) } \\
\text { Australia }\end{array}$ & Carbohydrates & $\begin{array}{l}\mathrm{n}=2353 ; \text { mean } \\
\text { age 12yrs }\end{array}$ & Australian & $\begin{array}{l}\text { Random } \\
\text { cluster sample }\end{array}$ & IVAN & $\begin{array}{l}\text { Age, sex, ethnicity, axial } \\
\text { length, BMI, MAPD, \& fellow } \\
\text { vessel calibre }\end{array}$ & $\begin{array}{l}\text { Children who consumed soft } \\
\text { drinks once or more per day } \\
\text { had significantly narrower } \\
\text { retinal arterioles ( } p=0.03) \text {, } \\
\text { a greater consumption of } \\
\text { carbohydrates was associated } \\
\text { with a narrowing of retinal } \\
\text { arterioles ( } p=0.01 \text { ) and a } \\
\text { widening of retinal venular } \\
\text { calibre }(p=0.002)\end{array}$ \\
\hline $\begin{array}{l}\text { Kelly et al (2011) } \\
\text { Netherlands }\end{array}$ & $\begin{array}{l}\text { Plant sterol } \\
\text { and -stanol }\end{array}$ & $\begin{array}{l}\mathrm{n}=30 \\
18-65 \mathrm{yrs}\end{array}$ & Dutch & $\begin{array}{l}\text { Randomised } \\
\text { control trial }\end{array}$ & IVAN & None stated & $\begin{array}{l}\text { Increased serum campesterol } \\
\text { concentrations were associated } \\
\text { with a wider retinal venular } \\
\text { diameter }(p=0.033)\end{array}$ \\
\hline
\end{tabular}


Table 1 continued. Studies examining the association between dietary factors and retinal microvasculature, by year of publication.

\begin{tabular}{|c|c|c|c|c|c|c|c|}
\hline $\begin{array}{l}\text { Reference; country/ } \\
\text { setting of study }\end{array}$ & $\begin{array}{l}\text { Nutrient/s } \\
\text { examined }\end{array}$ & $\begin{array}{l}\text { Sample size; } \\
\text { age }\end{array}$ & Ethnicity & Study type & $\begin{array}{l}\text { Method of } \\
\text { retinal vessel } \\
\text { measurement }\end{array}$ & Adjustments & Outcome; $p$ value \\
\hline $\begin{array}{l}\text { Kaushik et al (2009) } \\
\text { Blue Mountains Eye } \\
\text { Study }\end{array}$ & $\begin{array}{l}\text { Glyceamic } \\
\text { index }\end{array}$ & $\begin{array}{l}\mathrm{n}=2897 \\
>49 \mathrm{yrs}\end{array}$ & Australian & $\begin{array}{l}\text { Population } \\
\text { based cohort } \\
\text { study }\end{array}$ & IVAN & $\begin{array}{l}\text { Age, sex, systolic and diastolic } \\
\text { blood pressure, BMI, smoking, } \\
\text { educational qualifications, } \\
\text { fair of poor self-rated health, } \\
\text { diabetes mellitus, history of } \\
\text { coronary heart disease, and } \\
\text { total vegetable, saturated fat } \\
\text { and fish consumption }\end{array}$ & $\begin{array}{l}\text { Increasing Gl diets were } \\
\text { associated with retinal venular } \\
\text { calibre widening }(p=<0.01)\end{array}$ \\
\hline $\begin{array}{l}\text { Pemp et al (2010) } \\
\text { Vienna }\end{array}$ & Antioxidants & $\begin{array}{l}n=21 \\
18-35 y r s\end{array}$ & Italian & $\begin{array}{l}\text { Randomised, } \\
\text { double- } \\
\text { masked, } \\
\text { placebo } \\
\text { controlled, } \\
\text { parallel group } \\
\text { study }\end{array}$ & $\begin{array}{l}\text { Dynamic } \\
\text { Vessel } \\
\text { Analyser }\end{array}$ & None stated & $\begin{array}{l}\text { The administration of } \\
\text { antioxidants was associated } \\
\text { with a significant reduction } \\
\text { in vasoconstriction of retinal } \\
\text { arterioles }(p=0.040 \text { ) }\end{array}$ \\
\hline $\begin{array}{l}\text { Lim et al (2009) } \\
\text { Singapore }\end{array}$ & $\begin{array}{l}\text { Dietary fiber, } \\
\text { protein, fat, } \\
\text { cholesterol, } \\
\text { carbohydrate } \\
\text { and sugar } \\
\text { intakes }\end{array}$ & $\begin{array}{l}\mathrm{n}=823 ; \text { mean } \\
\text { age } 12.8 \mathrm{yrs}\end{array}$ & $\begin{array}{l}\text { Singapore } \\
\text { Chinese }\end{array}$ & $\begin{array}{l}\text { Population } \\
\text { based cohort } \\
\text { study }\end{array}$ & IVAN & $\begin{array}{l}\text { Age, gender, BMI, and mean } \\
\text { arterial blood pressure }\end{array}$ & $\begin{array}{l}\text { No significant association } \\
\text { existed between any of the } \\
\text { dietary constituents and retinal } \\
\text { vascular calibre }\end{array}$ \\
\hline $\begin{array}{l}\text { Kaushik et al (2008) } \\
\text { Blue Mountains Eye } \\
\text { Study }\end{array}$ & Fish & $\begin{array}{l}\mathrm{n}=2683 \\
>49 \mathrm{yrs}\end{array}$ & Australian & $\begin{array}{l}\text { Population } \\
\text { based cohort } \\
\text { study }\end{array}$ & IVAN & $\begin{array}{l}\text { Age, gender, MABP, BMI, } \\
\text { smoking, glucose, choles- } \\
\text { terol, white cell and platelet } \\
\text { counts, qualifications, } \\
\text { self-rated health, past history } \\
\text { of heart disease and total } \\
\text { vegetable and fat intakes }\end{array}$ & $\begin{array}{l}\text { Statistically significant associa- } \\
\text { tions were found between } \\
\text { an increased frequency of } \\
\text { fish consumption and wider } \\
\text { retinal arteriolar ( } p=0.002 \text { ) and } \\
\text { narrower retinal venular calibre } \\
(p=0.02)\end{array}$ \\
\hline
\end{tabular}


Table 1 continued. Studies examining the association between dietary factors and retinal microvasculature, by year of publication.

\begin{tabular}{|c|c|c|c|c|c|c|c|}
\hline $\begin{array}{l}\text { Reference; country/ } \\
\text { setting of study }\end{array}$ & $\begin{array}{l}\text { Nutrient/s } \\
\text { examined }\end{array}$ & $\begin{array}{l}\text { Sample size; } \\
\text { age }\end{array}$ & Ethnicity & Study type & $\begin{array}{l}\text { Method of } \\
\text { retinal vessel } \\
\text { measurement }\end{array}$ & Adjustments & Outcome; p value \\
\hline Kan et al (2007) USA & Dietary Fiber & $\begin{array}{l}n=15792 ; \\
45-64 y r s\end{array}$ & American & $\begin{array}{l}\text { Population } \\
\text { based cohort } \\
\text { study }\end{array}$ & IVAN & $\begin{array}{l}\text { Sex, race, smoking status, } \\
\text { occupation, education, } \\
\text { alcohol intake, diabetes } \\
\text { status, BMI, physical activity, } \\
\text { systolic and diastolic blood } \\
\text { pressure, serum lipids, dietary } \\
\text { factors from both food and } \\
\text { supplements and other } \\
\text { sources of fiber }\end{array}$ & $\begin{array}{l}\text { A high fiber consumption } \\
\text { was positively correlated with } \\
\text { wider retinal arteriolar calibre } \\
\text { ( } p=0.002) \text { and narrower venular } \\
\text { calibre }(p=0.011)\end{array}$ \\
\hline
\end{tabular}

